\title{
INCLUSIVE DESIGN EDUCATION: HOW TO GET IT RIGHT
}

\author{
Lisa LAMARRA and Avril THOMSON \\ Design, Manufacturing and Engineering Management, University of Strathclyde, Glasgow, \\ United Kingdom
}

\begin{abstract}
The study reported in this paper aims to understand graduate skills in relation to Inclusive Design (ID) knowledge, tools and methods and how these are related to the curriculum delivered throughout their degree programme. It focusses on students graduating from the Product Design Engineering (PDE) degree programme at the University of Strathclyde. Two research questions are addressed - What Inclusive Design skills do Product Design Engineering graduates typically possess? How might the current curriculum be reviewed to facilitate the enrichment of Inclusive Design skills? Findings report on prevalence of ID tools, methods and skills in graduating students' project work. A comparison is drawn between evidenced application of ID methods and tools and perceived skills captured from survey results. Reflections on current curriculum and pedagogical approaches are made with discussion focusing on potential adaptations to enhance ID skills in graduates completing the PDE course. Trends including which ID tools and methods are used most/least often or collectively are reported. A comparison is drawn between evidenced application of ID methods and tools and perceived skills captured from survey results. Reflections on current curriculum and pedagogical approaches are made with discussion focusing on potential adaptations to enhance ID skills in graduate Product Design Engineer cohorts.
\end{abstract}

Keywords: Inclusive design, education, product design engineering, curriculum design, design methods

\section{INTRODUCTION}

\subsection{Project background}

Population ageing represents an unprecedented global challenge which is predicted to have a considerable impact in the daily life of individuals all around the globe [1]. As reported by the World Health Organisation, the 'over 60' age range is expected to double by 2050 . The forecast of a progressively older population not only implies that the life expectancy index of most countries will increase, but also results in more individuals having to deal with age-related disabilities. The estimated number of people living with a disability is one billion and already represents one of the most significant sources of expenditure for health care worldwide [2]. The inevitability of these global trends has prompted research in various fields, design being among those, and has produced outputs ranging from labour force shortage predictions to income security strategies [1]. Risk mitigation, however, represents only one angle for tackling these issues: a completely different alternative is offered by advocates of ID, who strongly believe in its potential to minimise the impact of an ageing population by changing the way industry and designers look at products and services. This approach is based on the principle that different individuals have different capability types and levels [3] Diversity should be considered to develop solutions that are suitable to be used by individuals belonging to the entire spectrum [4].

Despite its vast potential, ID in industry is only implemented to a limited extent. Although positive examples have been studied in the last decade, several economical and practical barriers hinder the adoption of an ID approach. Awareness of its main principles is also a problem [5]: although ID modules are integrated in several university courses and curricula, the uptake in industry is quite low. Observing how significant the conflict between education and industry is in relation to the global challenges previously discussed has prompted the need to investigate this matter further. This study will therefore 
focus on understanding the factors involved to offer a novel perspective on how educational institutions can drive a sustainable shift and influence industry practice.

\section{INCLUSIVE DESIGN}

\subsection{What is Inclusive Design and why is it needed?}

Developed as a user-focused approach incorporating principles such as accessibility and access to artefacts and technology, ID differentiates itself from traditional design approaches in several ways. Firstly, its primary objective is to "create equality within society through the eradication of social exclusion' [6]. ID, therefore, strives to meet the needs of a wider spectrum of individuals, including able-bodied users and those with specific needs [7]. Demographic changes are leading to an increasing number of older people world-wide' [8]. The United Nations Department of Economic and Social Affairs reports that in 2018 individuals over 65 years of age globally overcounted children aged five or younger, and the 80+ age range is forecast to triple and reach 426 million (2019). Figure 1 provided a graphical view of population.

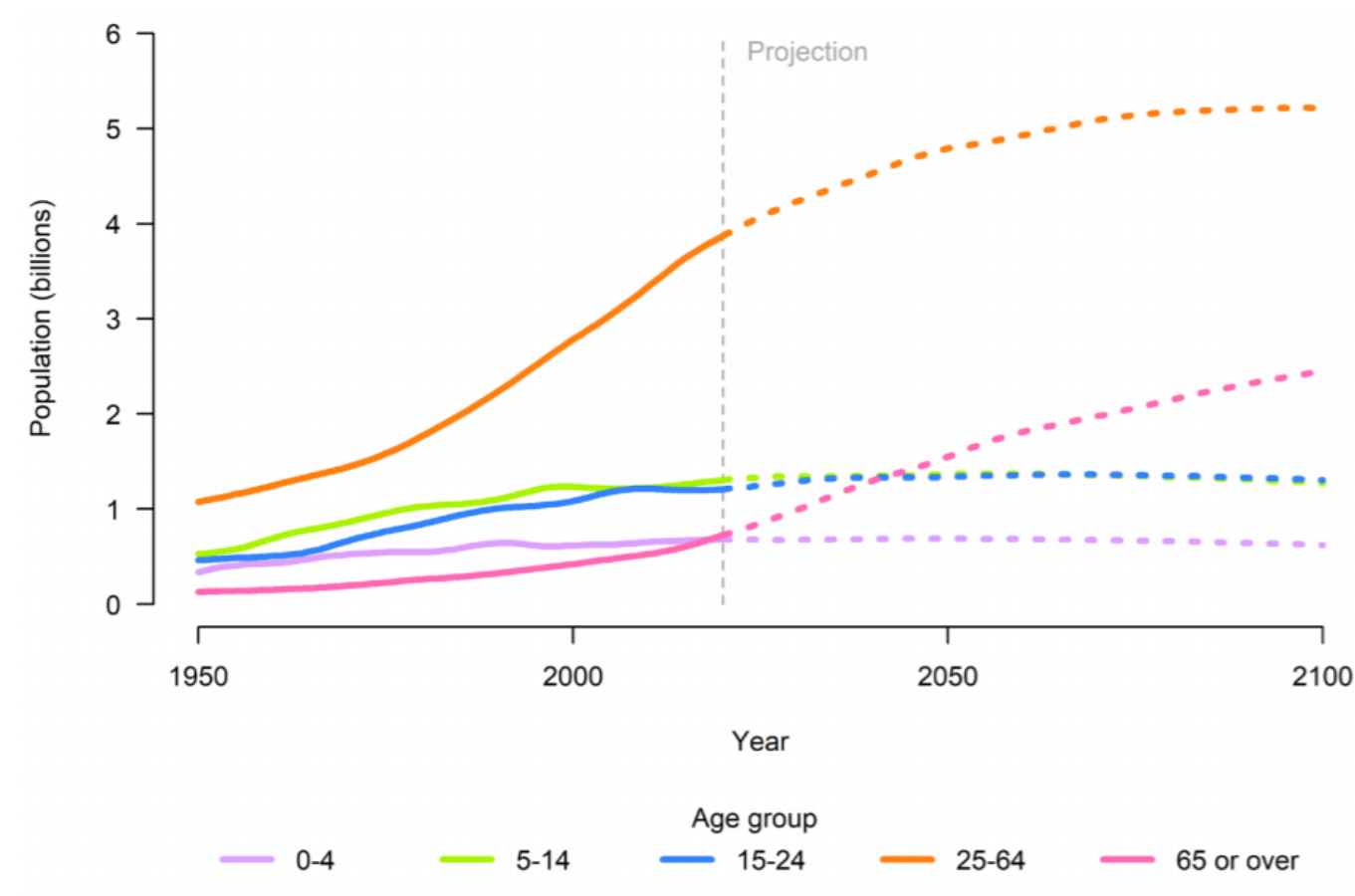

Figure 1. Estimated and projected global population by broad age group, 1950-2100. Source: United Nations, Department of Economic and Social Affairs, Population Division (2019). World Population Prospects 2019

As a direct consequence of the ageing process, the global disability index has experienced a rapid growth. In countries where the average life expectancy index is over 70 years, individuals spend more than 10 per cent of their lives living with one or more disabilities (Disabled World, 2019). A 2011 report by the World Health Organisation confirmed that the world's largest minority is represented by people who live with disabilities, accounting for approximately 15 per cent of the global population.

\subsection{What are the challenges of ID implementation in industry}

The main difficulty that design firms and manufacturers face is user involvement, and the primary reason for this is a lack of budget and time. It is a unanimous opinion among ID researchers that these two factors are most likely to hinder the success of many inclusive projects - and user-centred projects in general. This is often because organisations often do not budget for additional resources to be dedicated to ID [9] or because other activities are prioritised [10]. Table 1. Outlines the more commonly attributable sources sighting barriers to ID. 
Table 1. Summary of barriers to Inclusive Design

\begin{tabular}{|c|c|}
\hline Barrier & Source of Evidence \\
\hline Lack of time and budget & Don and Petrick, 2003; Sims, 2003; Dong, 2004 \\
\hline Lack of awareness & Evans, 1998; Carse et al., 2010; Cremers et al., 2013 \\
\hline Lack of expertise & $\begin{array}{l}\text { Vanderheiden and Tobias, 1998; Bruseberg and McDonagh-Philp, 2002; } \\
\text { Langdon et al., } 2015\end{array}$ \\
\hline Problems with methods/tools & Dong, et al. 2002; Crilly, 2005; Goodman et al., 2006 \\
\hline Logistics and practicalities & Crilly and Clarkson, 2006 \\
\hline Perceived insufficient commercial value & Goodman et al., 2006; (Hua Dong,Keates and Clarkson, 2004) \\
\hline
\end{tabular}

\subsection{Literature review key findings}

A summary of the literature is presented in the table below.

\section{Table 2. Summary of key findings generated by the literature review}

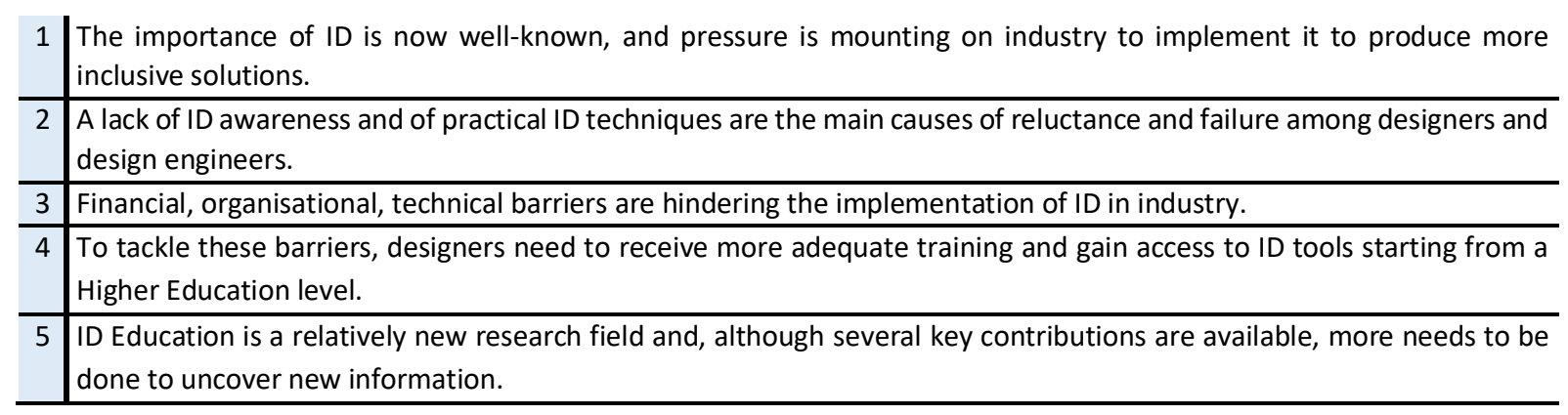

\subsection{Research knowledge gap}

Several publications have documented the drivers, challenges and barriers of ID implementation, including the pivotal role of educators and designers to improve the uptake of ID among students and professionals. This paper has focused on narrowing the knowledge gap by investigating the skillset, knowledge and secondary competencies that graduates from the department of Design, Manufacturing and Engineering Management possess. A novel contribution to the field of inclusive design education is made by providing recommendations on possible ways to facilitate the development of ID skills in a university context.

\subsection{Research questions}

The gaps in the literature discussed were used as a guide to formulate research questions. The two questions that were developed aided by the Project Aim of the study are as follows:

RQ1 What Inclusive Design skills do Product Design Engineering graduates typically possess? RQ2 How might the current curriculum be adapted to influence the enrichment of Inclusive Design skills?

\section{METHODOLOGY}

\subsection{Research design}

A research process was developed which implemented two research strategies, presented in Figure 2. This consists in the use of an on-line questionnaire used for collecting individual students' perceptions and knowledge of ID and a second method using coding to evaluate recurring key words and phrases to conduct a 'content analysis' to identify the application of ID methods in a sample of final year projects. The two approaches were developed from Wilson's research methods on the facilitation of inclusive design [18] and an inclusive design framework 'Field Guide to Human-Centred Design' [19] 


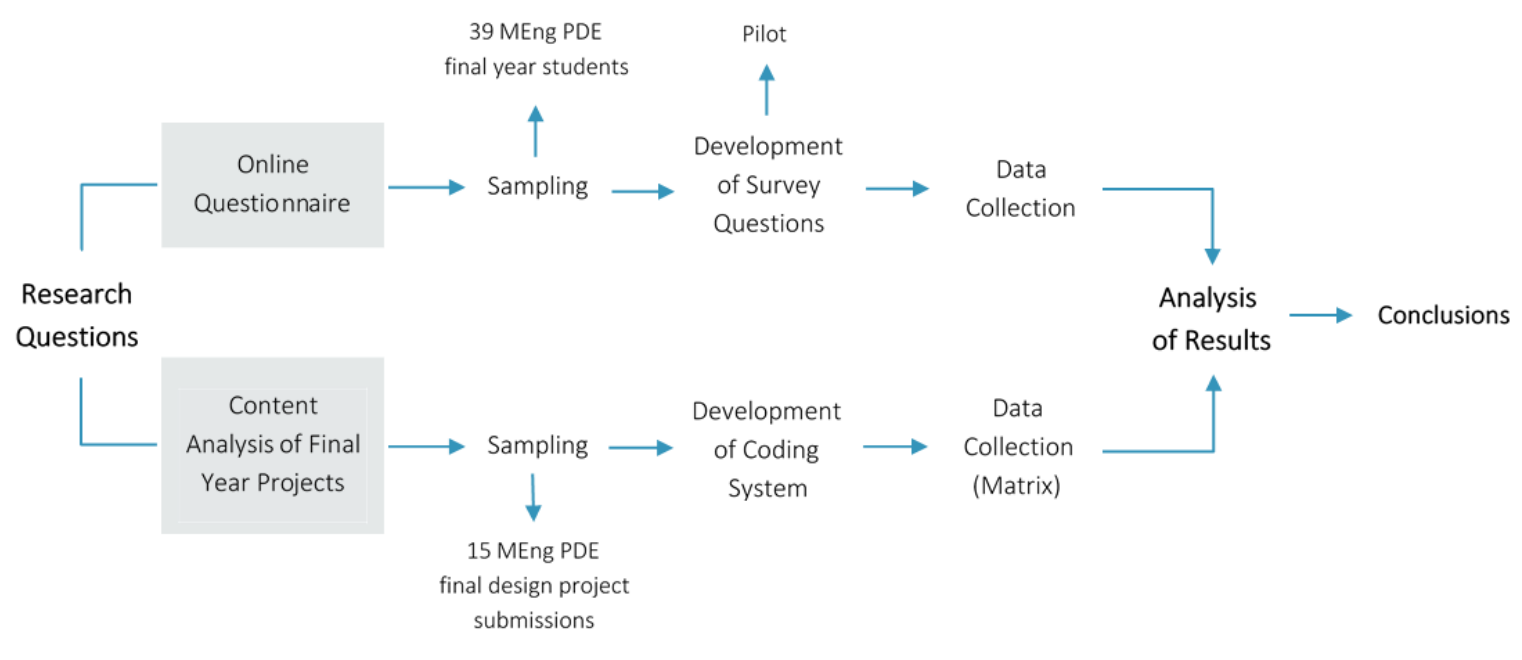

Figure 2. Research Process Diagram

\section{FINDINGS}

\subsection{Summary of findings}

The data collected from the two chosen research methods was coded and examined. The analysis of final year projects provided secondary data on students' use of ID methods as well as on their preferred methodologies and their choice of design foci/approaches. The online questionnaire yielded insights on what students believe their knowledge, skills and ID implementation levels are. Elements of statistical analysis were used to understand and interpret the information, and conclusions were drawn accordingly. These are summarised in tables 3 and 4.

\section{Online Questionnaire}

Table 3. Key findings from the online questionnaire

\begin{tabular}{c|l}
\hline 1 & $\begin{array}{l}\text { Students' knowledge of ID methods and tools is very good. At least } 50 \% \text { of respondents state to be aware of } 9 \text { ID } \\
\text { methods out of the } 10 \text { listed. }\end{array}$ \\
\hline 2 & $\begin{array}{l}\text { Students' use of ID methods in university is frequent, although some methods prevail over others. Personas, } \\
\text { Observations, User Feedback, Focus Groups and User Testing are the most popular methods. }\end{array}$ \\
\hline 3 & $\begin{array}{l}\text { The Cambridge Exclusion Calculation tool is not known to students as an ID evaluation method. This is because little } \\
\text { to no emphasis is given to it in class. }\end{array}$ \\
\hline 4 & $\begin{array}{l}\text { Although the importance and benefits of ID are recognised, only 51\% of students report to be planning on using ID } \\
\text { methods in their individual design projects. Students who intend to do so, mainly predict to be using } 3 \text { or } 4 \text { ID methods. }\end{array}$ \\
\hline 5 & $\begin{array}{l}\text { Former students who are currently employed in the design/manufacturing industry report that ID principles are } \\
\text { indeed adopted in their place of employment. }\end{array}$
\end{tabular}

\section{Content Analysis of Final Year Projects}

\section{Table 4. Key findings from the content analysis of final year projects}

\begin{tabular}{c|l}
1 & $\begin{array}{l}\text { Evidence was found of the use of } 2 \text { to } 7 \text { ID methods, highlighting that students are aware of their existence and } \\
\text { purpose. }\end{array}$ \\
\hline 2 & $\begin{array}{l}\text { Some ID methods are more popular than others: user feedback and observations are included in } 80 \% \text { to } 87 \% \text { of } \\
\text { submissions. Testing prototypes, taking part in focus groups and consulting experts are often used to gather } \\
\text { feedback. }\end{array}$ \\
\hline 3 & $\begin{array}{l}\text { Over 50\% of submissions examined show evidence of iteration of one or two ID methods. This demonstrates } \\
\text { students are aware of the importance of using an iterative approach of understanding user's needs. User/expert } \\
\text { feedback focus groups and empathetic modelling appear twice in } 20 \% \text { to } 45 \% \text { of submissions. }\end{array}$ \\
\hline 4 & $\begin{array}{l}\text { No evidence of use of Inclusive Design Process is recorded. Although students choose to use ID methods, their } \\
\text { methodology of choice is often a standard design framework or, in some cases, a user-focused one. There seems to }\end{array}$ \\
\hline
\end{tabular}




\subsection{General ID understanding}

Results obtained from the online survey suggested that students' perceptions towards ID are quite positive. Respondents recognise the importance of designing inclusively and, when asked to self-assess their understanding of ID principles, evaluate their knowledge as mostly adequate or good. Benefits of ID appear to be well-understood by $95 \%$ of respondents. This shows that the current teaching structure and approach has produced good results, or has at least raised awareness on the topic of ID.

\subsection{Use and selection of ID methodologies and ID approaches}

A significant disparity of results was identified after comparing students' responses on ID methodologies and approaches survey Q2, within the contents of final year submissions. On one hand, $72 \%$ of respondents evaluate their understanding of ID principles as 'adequate', 'good' or 'excellent' and consider inclusive design 'moderately important' or 'extremely important', survey Q3. On the other hand, there is little to no evidence of individual projects selecting ID Methodologies where mentioning key words such as 'inclusive design' and 'design for inclusion' were observed.

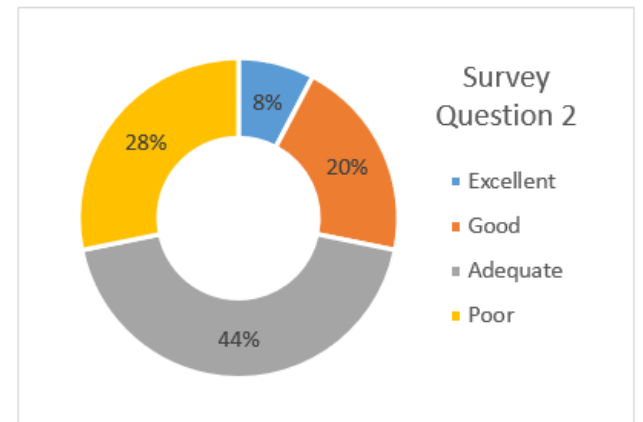

Figure 4. Understanding of ID process, methods and tools

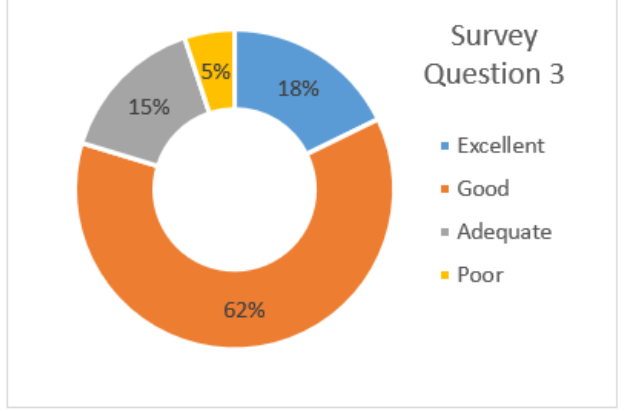

Figure 5. Understanding of the benefits of ID.

\section{RECOMMENDATIONS}

\subsection{Summary}

The comparison and analysis of the two data sets have uncovered some interesting insights on skills that PDE graduates possess including potential abilities which require further development. The research highlighted that the current course content includes a considerable amount of teaching ID methods which, have proven to be effective. However, improvements in the curriculum could be made to facilitate the assimilation of ID methods and processes more robustly. Therefore, this study highlights the following recommendations:

- Inclusive Design methods, tools and techniques that appear to be less clear should be covered in more depth. Greater emphasis should be given to understanding what type of information can be extracted from each method and how the data gathered can be utilised in a design project.

- Class exercises and case studies would be useful to demonstrate advantages and disadvantages of ID methods to help student's confidence levels in using these techniques.

- It is recognised that user involvement requires extensive resources. However, institutions should consider investing more in the use of practical activities that encourage student-user interaction: empathic modelling sessions in class, live focus groups, interviews with experts, prototype testing sessions and guidance on conducting interviews would all be beneficial.

- Greater emphasis should be placed on the communication of ID techniques such as the Cambridge Inclusive Design Process. Comparing them with standard product design frameworks. Embedding ID techniques throughout the length of the course would increase awareness and knowledge.

Discussion and confrontation on the selection of a correct research methodology and design focus should be encouraged: Student are already designing inclusively but often fail to identify that they are doing so. This is probably due to a lack of clarity surrounding ID-specific frameworks and approaches. More class time should therefore be committed to shedding light on how to correctly select suitable options. 


\section{REFERENCES}

[1] Bloom, D.E., Canning, D. and Lubet, A. (2015) 'Global population aging: Facts, challenges, solutions \& perspectives'. Daedalus, 144 (2), pp. 80-92.

[2] Ogura, S. and Jakovljevic, M.M. (2018) 'Global Population Aging-Health Care, Social and Economic Consequences'. Frontiers in public health, 6335.

[3] Johnson, D., Clarkson, J. and Huppert, F. (2010) 'Capability measurement for inclusive design'. Journal of Engineering Design, 21 (2-3), pp. 275-288.

[4] Langdon, P. et al. (2015) 'A framework for collecting inclusive design data for the UK population'. Applied Ergonomics, 46 318-324.

[5] Sims, R. (2003) 'Design for all': methods and data to support designers. (O) Ruth Elise Sims.Soiferman, L.K. (2010) 'Compare and Contrast Inductive and Deductive Research Approaches'. Online Submission.

[6] Clarkson, J P. and Coleman, R. (2015) 'History of Inclusive Design in the UK'. Applied Ergonomics, 46 235-247.

[7] Goodman-Deane, J., Langdon, P. and Clarkson, J. (2010) 'Key influences on the user-centred design process'. Journal of Engineering Design, 21 (2-3), pp. 345-373.

[8] Dong, H., Keates, S. and Clarkson, P.J. (2004) Published. 'Inclusive Design in Industry: Barriers, Drivers and the Business Case'. 2004 Berlin, Heidelberg. Springer Berlin Heidelberg, pp.305319.

[9] Don, A. and Petrick, J. (2003) 'User requirements'. Design research: Methods and perspectives, 22.

[10] Bruseberg, A. and McDonagh, D. (2002) 'Focus Groups to Support the Industrial/Product Designer: A Review Based on Current Literature and Designers' Feedback'. Applied ergonomics, 33 27-38.

[11] Sims, R. (2003) 'Design for all': methods and data to support designers. (C) Ruth Elise Sims.

[12] Carse, B., Thomson, A. and Stansfield, B. (2010) 'Use of biomechanical data in the Inclusive Design process: packaging design and the older adult'. Journal of Engineering Design, 21 (2-3), pp. 289-303.

[13] Cremers, A.H.M., Neerincx, M.A. and de Jong, J.G.M. (2013) Published. 'Inclusive Design: Bridging Theory and Practice'. 2013 Berlin, Heidelberg. Springer Berlin Heidelberg, pp.323332.

[14] Vanderheiden, G. and Tobias, J. (1998) 'Barriers, Incentives and Facilitators for Adoption of Universal Design Practices by Consumer Product Manufacturers'. Proceedings of the Human Factors and Ergonomics Society Annual Meeting, 42 (6), pp. 584-588.

[15] Langdon, P. et al. (2015) 'A framework for collecting inclusive design data for the UK population'. Applied Ergonomics, 46 318-324.

[16] Goodman, J. et al. (2006) Factors Involved in Industry's Response to Inclusive Design. London: London: Springer London.

[17] Dong, H., Keates, S. and Clarkson, P.J. (2004) Published. 'Inclusive Design in Industry: Barriers, Drivers and the Business Case'. 2004 Berlin, Heidelberg. Springer Berlin Heidelberg, pp.305319.

[18] Wilson, N. (2016) Capturing the sports design process to facilitate the uptake of inclusive design. Thesis [Ph. D] -- University of Strathclyde, 2016.

[19] IDEO, D.K. (2015) 'The field guide to human-centered design'. IDEO Canada. 